\title{
Os esquemas de gênero e suas cicatrizes irreversíveis: ainda sobre a relação entre mulheres e ciências
}

Gender Schemas and their Irreversible Scars: Still About the Relationship between Women and Science

\author{
Alinne de Lima Bonetti' (iD) 0000-0003-0810-5926 \\ Alana Pacheco dos Reis Verani ${ }^{2}$ iD 0000-0003-0814-1054
}

'Universidade Federal de Santa Catarina, Programa de Pós-Graduação em Antropologia Social e Departamento de Antropologia, Florianópolis, SC, Brasil.

88040-900 - ant@contato.ufsc.br

${ }^{2}$ Universidade Federal de Santa Catarina, Programa de Pós-Graduação em Antropologia Social, Florianópolis, SC, Brasil. 88040-900 - ant@contato.ufsc.br

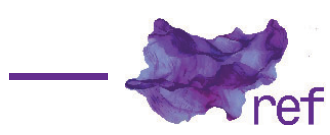

GROSSI, Miriam Pillar; REA, Caterina Alessandra (Orgs.).

Teoria Feminista e Produção de Conhecimento Situado: Ciências Humanas, Biológicas, Exatas e Engenharias.

Florianópolis: Tribo da llha; Salvador: Devires, 2020.

Teoria Feminista e Produção de Conhecimento Situado: Ciências Humanas, Biológicas, Exatas e Engenharias (Miriam GROSSI; Caterina REA, 2020) tem como proposta refletir, por meio da perspectiva teórica feminista, sobre os campos da ciência e da produção científica a partir do entendimento de que qualquer forma de saber é produto de atividades humanas e práticas coletivas interconectadas. Cada artigo demonstra, a partir de suas próprias problemáticas e objetivos, que a produção de conhecimento é permeada de disputas, relações de poder, hierarquias e desigualdades sociais, de maneira que o conhecimento e suas formas de produção não devem ser entendidos como apartados da sociedade. Recobrindo as mais diferentes áreas da produção científica, os dezessete artigos que compõem o volume estão organizados em quatro partes: I) Gênero no campo da Antropologia, II) Mulheres e teorias feministas nas Ciências Humanas, III) Mulheres nas engenharias e Ciências Exatas, IV) Mulheres nas Ciências Biomédicas. Além da riqueza do conteúdo, é digno de nota o cuidadoso projeto gráfico da publicação, que conta com uma belíssima capa, assinada pela artista gráfica e colagista feminista brasileira, Elisa Riemer, que é um estímulo a mais à leitura.

A publicação traz textos oriundos de diferentes projetos de pesquisa sobre o tema Gênero e Ciências e, sendo assim, reúne diferentes pesquisadoras e pesquisadores, em distintos momentos de sua trajetória na formação acadêmica. Ao lado de importantes referências do campo de estudos de gênero e ciência, como llana Lowy, Miriam Grossi, Luzinete Minella e 
Margaret Lopes, encontramos reflexões de autoras e autores que, à época, estavam em processo de iniciação científica, além de mestrandas/os, doutorandas/os e pós-doutorandas/ os, o que confere um pluralismo e uma riqueza ímpar ao livro, proporcionando uma reflexão sobre o próprio processo de, na ausência de melhor expressão, socialização científica e a constituição do campo de estudos de gênero e ciências. Neste sentido, para as estudiosas e estudiosos do tema, outro aspecto relevante da coletânea é o de que as/os 18 autoras/es têm, predominantemente, formação na área das Ciências Humanas - história, filosofia, educação, ciências sociais, antropologia, comunicação, museologia etc. -, sendo poucas e poucos as e os que iniciaram suas trajetórias acadêmicas em áreas relativas às Ciências Biomédicas ou Exatas - como graduação em ciências biológicas e geologia, por exemplo -, mas que acabaram se voltando às Humanas. Esse dado nos diz muito sobre as preocupações em torno da relação gênero e ciências o e desenvolvimento deste campo de estudos e pesquisas, consonante com os recentes e crescentes movimentos e coletivos brasileiros em torno da relação mulheres nas ciências, tais como o Parents in Science.

O livro representa um importante marco para o fortalecimento do campo de pesquisa de gênero e ciências, em ebulição recente no Brasil, sobretudo a partir do interesse crescente das cientistas das áreas biomédicas, tecnológicas e exatas, assim como a própria variedade de perspectivas sobre o assunto contidas nele. Os artigos se situam nas quatro linhas fundamentais dos estudos de gênero e ciência estabelecidas por autoras referências no tema, como Londa Schiebinger: estudos sobre mulheres pioneiras, mulheres na ciência, análise de epistemologias feministas, estudos sobre a intersecção de conhecimentos científicos e conhecimentos de gênero e sexualidade.

A primeira parte do livro "Gênero no campo da Antropologia" contém artigos escritos por Candice Vidal e Souza, Bruna Klöppel, Miriam Pillar Grossi, Francine Pereira Rebelo, Vinicius Kauê Ferreira, Giovanna Lícia Rocha Triñanes Aveiro e Tania Pérez-Bustos; e apresentam como contribuição análises sobre como o gênero é um fator que pode trazer limites sociais postos para o desenvolvimento de carreiras científicas e da própria disciplina antropológica, mas que são justamente as cientistas mulheres que percebem esses limites e trazem questionamentos e críticas feministas à ciência e novas possibilidades de reimaginar as práticas acadêmicas.

Na segunda parte, "Mulheres e teorias femininas nas Ciências Humanas", as autoras Fernanda Azeredo de Moraes, Julia Moura Godinho, Miriam Pillar Grossi, Betina Stefanello Lima e Izabela Liz Schlindwein nos fazem refletir sobre a importância do resgate de trajetórias de mulheres cientistas e da sua contribuição para a reconstituição de novas memórias dos feminismos, assim como para expansão dos estudos de relações de gênero e feminismos.

Na terceira parte, "Mulheres nas engenharias e Ciências Exatas", as autoras Carla Giovana Cabral e Luciana Rosar Fornazari Klanovicz analisam quantitativa e qualitativamente - aumento do número de mulheres nas engenharias, pontuando a íntima relação entre a predominância da presença feminina em determinadas áreas de conhecimento e a sua desqualificação, relevando as dinâmicas de funcionamento das convenções de gênero no campo científico. Por fim, na quarta parte, "Mulheres nas Ciências Biomédicas", as autoras llana Löwy, Maria Margaret Lopes, Felipe Bruno Martins Fernandes, Caterina Alessandra Rea e Miriam Pillar Grossi analisam como os estudos sobre mulheres e carreiras científicas tornaram visíveis as dificuldades encontradas e a dimensão dos obstáculos para a paridade e equidade entre os sexos. Derivadas desta temática, são problematizadas as peculiaridades encontradas no acesso de mulheres aos espaços de discussão e produção de conhecimento, assim como se dá a articulação entre gênero, lógica do prestígio acadêmico e financiamento.

A coletânea nos faz lembrar que a preocupação sobre a relação entre mulheres e ciências é parte fundante da crítica feminista à ciência, portanto, constitutiva da epistemologia feminista. Embora seja eminentemente interdisciplinar, a produção de fôlego se dá predominantemente no campo das ciências humanas, que tem lançado olhar sobre os mais distintos campos científicos, como demonstra o volume. O seu diferencial está em discutir teoria feminista e produção de conhecimento situado nas mais diferentes áreas científicas, o que aporta uma importante contribuição para a análise das mulheres na ciência, ela inclui uma reflexão de fôlego sobre o próprio campo das ciências humanas, em especial da Antropologia; uma reflexão que tende a ser deixada de lado nos intensos debates contemporâneos sobre a relação mulheres e ciências, que vem sendo capturada e hegemonizada pelas áreas STEM, sigla em inglês para Ciência, Tecnologia, Engenharia, Matemática.

Cabe problematizar esse investimento e interesse crescentes, que legitimamente têm buscado aprofundar a presença das mulheres em áreas científicas ainda resistentes à igualdade e gênero. Contudo, e em diálogo com a Antropologia Feminista, se tomarmos gênero como um princípio da vida social humana (Henrietta MOORE, 1988), que remete a "formas locais e específicas de relações sociais e de desigualdade social" (Michele ROSALDO, 1995, p. 22), constitutivas de sistemas de distribuição desigual de prestígios e privilégios (Sherry ORTNER; Harriet WHITEHEAD, 1981), nos perguntamos: seriam as humanas, ciências mais femininas do que as 
biomédicas, as matemáticas ou engenharias? Estariam imunes às ingerências das convenções de gênero que organizam a cultura científica, distribuindo igualmente prestígio e privilégios entre cientistas homens e mulheres? Ou estaríamos frente a um processo de feminização das ciências humanas diante da masculinização das biomédicas, das matemáticas e engenharias? Os textos reunidos neste livro nos fornecem elementos e ferramentas para a compreensão deste fenômeno. Em particular, destacamos os esquemas de gênero integrantes do mundo da ciência denunciados por llana Löwy em seu capítulo, responsáveis pela lenta transformação da paisagem científica no que tange à igualdade entre homens e mulheres. Tal cenário produz, segundo a autora, cicatrizes irreversíveis, outra potente chave analítica para se compreender a trajetória das mulheres cientistas. Tais esquemas de gênero e as suas cicatrizes irreversíveis ressoam nos textos da coletânea que, em conjunto, nos provocam a refletir sobre a cultura científica, suas convenções de gênero e os seus atravessamentos por distintos marcadores sociais. Tendo-se em vista as características da publicação, esperamos ter feito jus à sua relevância tanto epistemológica quanto histórica, de maneira a explicitar por que precisamos, ainda, problematizar as relações entre mulheres e as ciências.

\section{Referências}

GROSSI, Miriam Pillar; REA, Caterina Alessandra (orgs.). Teoria Feminista e Produção de Conhecimento Situado: Ciências Humanas, Biológicas, Exatas e Engenharias. Florianópolis: Tribo da llha; Salvador: Devires, 2020.

ORTNER, Sherry B.; WHITEHEAD, Harriet. "Accounting for sexual meanings". In: ORTNER, Sherry B.; WHITEHEAD, Harriet (Eds.). Sexual Meanings: the cultural construction of gender and sexuality. Cambridge: Cambridge University Press, 1981. p. 1-27.

ROSALDO, Michelle. "O uso e o abuso da Antropologia: reflexões sobre o feminismo e o entendimento intercultural". Horizontes Antropológicos, Porto Alegre, ano 1, n. 1, p. 11-36, jan./ jun. 1995.

MOORE, Henrietta L. Feminism and anthropology. Minneapolis: University of Minnesota Press, 1988.

Alinne de Lima Bonetti (alinne.bonetti@ufsc.br) é Professora Adjunta da UFSC/ Departamento de Antropologia, integrante do Núcleo de Identidade de gênero e Subjetividade (NIGS) e colaboradora do Tuna - gênero, educação e diferença, da Unipampa. Temas de interesse e pesquisa: antropologia e teoria feminista, gênero, poder, alteridades complexas e desigualdades.

Alana Pacheco dos Reis Verani (alanareisverani@gmail.com) é mestranda em Antropologia Social pela Universidade Federal de Santa Catarina com bolsa de mestrado CNPq. Pesquisadora vinculada ao Núcleo de Identidades de Gênero e Subjetividades (NIGS/ UFSC) e, enquanto mestranda, pesquisa as relações entre maternidade, carreira científica e antropólogas. Possui graduação em História pela Universidade Federal Fluminense. 


\section{COMO CITAR ESTE ARTIGO DE ACORDO COM AS NORMAS DA REVISTA}

BONETTI, Alinne de Lima; VERANI, Alana Pacheco dos Reis. "Os esquemas de gênero e suas cicatrizes irreversíveis: ainda sobre a relação entre mulheres e ciências". Revista Estudos Feministas, Florianópolis, v. 29, n. 3, e78320, 2021.

\section{CONTRIBUIÇÃO DE AUTORIA}

As autoras contribuíram igualmente.

FINANCIAMENTO

Não se aplica.

\section{CONSENTIMENTO DE USO DE IMAGEM}

Não se aplica.

\section{APROVAÇĀO DE COMITÊ DE ÉTICA EM PESQUISA}

Não se aplica.

\section{CONFLITO DE INTERESSES}

Não se aplica.

\section{LICENÇA DE USO}

Este artigo está licenciado sob a Licença Creative Commons CC-BY 4.0 International. Com essa licença você pode compartilhar, adaptar, criar para qualquer fim, desde que atribua a autoria da obra.

\section{HISTÓRICO}

Recebida em $17 / 11 / 2020$

Aceita em 25/01/202 